\title{
Magnetic Properties of $\mathrm{Fe}_{3} \mathrm{C}$ Thin Film Prepared by the IBS Method
}

\author{
Takashi Hamaya, Junji Oikawa, Masaaki Doi, Hidefumi Asano, and Masaaki Matsui \\ Faculty of Engineering, Nagoya Univ., Furo-cho, Chikusa-ku, Nagoya 464-8603
}

The magnetic properties of $\mathrm{Fe}-\mathrm{C}$ thin film prepared by the ion-beam sputtering method (IBS) using a composite target were investigated. A single-phase $\mathrm{Fe}_{3} \mathrm{C}$ thin film was obtained from as-deposited amorphous $\mathrm{Fe}-\mathrm{C}$ thin films after heated up to $400^{\circ} \mathrm{C}$. From magnetization measurement and $\mathrm{X}$-ray diffraction, it was confirmed that the $\mathrm{Fe}_{3} \mathrm{C}$ film is single-phase without any impurity phase. Hyperfine parameters were estimated from the results of conversion electron Mössbauer spectroscopy (CEMS) measurement. The central values of the hyperfine field $\left(B_{\mathrm{hf}}=205 \mathrm{kOe}\right)$, isomer shift (IS $\left.=0.20 \mathrm{~mm} / \mathrm{s}\right)$, and quadrupole shift $(\mathrm{QS}=0.03 \mathrm{~mm} / \mathrm{s})$ for the film are consistent with those for bulk $\mathrm{Fe}_{3} \mathrm{C}$.

Key words: $\mathrm{Fe}_{3} \mathrm{C}$ thin film, ion-beam sputtering (IBS), conversion electron Mössbauer spectroscopy (CEMS), hyperfine structure.

\section{Introduction}

The crystal structure and magnetic properties of $\mathrm{Fe}_{3} \mathrm{C}$ compound have been investigated extensively for a long time, both from the viewpoint of pure physics and from that of the material's application as carbon steel ${ }^{1-5}$.

Recently, Fe-C alloy films ${ }^{6), 7)}$ have received considerable attention on account of their soft magnetic properties $^{6), 8), 9)}$. On the other hand, there have been only a few reports on $\mathrm{Fe}_{3} \mathrm{C}$ thin films ${ }^{10)}$,11). In view of the low solubility between $\mathrm{Fe}$ and $\mathrm{Fe}_{3} \mathrm{C}$ at high temperatures, the combination of $\mathrm{Fe}$ and $\mathrm{Fe}_{3} \mathrm{C}$ has a potential for practical application as a stable magnetic multilayer GMR sensor at high temperatures. In this paper, we report the preparation of a single-phase $\mathrm{Fe}_{3} \mathrm{C}$ thin film by the IBS method. Generally, to obtain a thin film with stoichiometric composition by the sputtering method, the composition of the target and the deposition conditions such as gas pressure, substrate temperature, deposition rate and so on, are important. It is difficult to get a reproducible stoichiometric thin film, when an ordinarily sintered or compounded target is used, because of the large difference between the sputtering rates for $\mathrm{Fe}(2.0$ atoms $/ \mathrm{Ar}^{+}$ion $)$and $\mathrm{C}\left(0.7\right.$ atom $/ \mathrm{Ar}^{+}$ion $){ }^{12)}$ in the present case. However, it is possible to prepare an easily reproducible $\mathrm{Fe}_{3} \mathrm{C}$ thin film by using a strictly designed composite target. In this paper, we report the crystal structure and magnetic properties of an Fe-C thin film prepared by the ion-beam sputtering method (IBS).

\section{Experimental Procedure}

$\mathrm{Fe}-\mathrm{C}$ thin films were prepared by the conventional ionbeam sputtering (IBS) method. The base pressure and sputtering pressure of the IBS apparatus were $<9 \times 10^{-7}$ Torr and $3.2 \times 10^{-4}$ Torr, respectively. The beam current and beam voltage of $\mathrm{Ar}^{+}$ions were $40 \mathrm{~mA}$ and $1000 \mathrm{~V}$, respectively. The deposition rate was $\sim 0.4 \AA / \mathrm{s}$ for $\mathrm{Fe}-\mathrm{C}$, and the substrate temperature was fixed at $\sim 50{ }^{\circ} \mathrm{C}$. We used a glass (Corning \#7059) substrate. The thickness of the film was fixed at $3000 \AA(5000 \AA$ for CEMS measurement). We used a composite target with $5 \mathrm{~N}$ carbon chips $(10 \mathrm{~mm} \times 10 \mathrm{~mm})$ fixed to an Fe $(75 \mathrm{~mm} \phi$ : 3N) target (Fig. 1). Three different composite targets were prepared with the area ratio, $\mathrm{Fe}: \mathrm{C}=$ (1) $52.4: 47.6$, (2) 49.0:51.0, and (3) 45.1:54.9, respectively. The sample numbers are the same as the target numbers. It should be mentioned that in the case of using a sintered target with $\mathrm{Fe}: \mathrm{C}=3: 1$, the composition of the thin films was not reproducible. It is considered that the composition of the target surface changed gradually in each sample preparation procedure because of the large difference in sputtering rates between $\mathrm{Fe}$ and $\mathrm{C}$. Accordingly, for the preparation of reproducible $\mathrm{Fe}-\mathrm{C}$ thin film, it is necessary to use a composite target with a strictly controlled area ratio of $\mathrm{Fe}$ to carbon chip. The magnetization was measured with a conventional vibrating sample magnetometer (VSM). The temperature dependence of magnetization was measured in the magnetic field of 10 $\mathrm{kOe}$ in a vacuumed atmosphere $\left(<1.0 \times 10^{-5} \mathrm{Torr}\right)$ with heating (cooling) velocity of $4.5^{\circ} \mathrm{C} / \mathrm{min}$. X-ray diffraction (XRD) with a $\mathrm{Cu}$ target was used for the structural analysis. The hyperfine structures were measured by conversion electron Mössbauer spectroscopy (CEMS) at room temperature. The size of the sample for the CEMS was $3 \times 3 \mathrm{~cm}^{2}$.

\section{Results and Discussion}

\subsection{Magnetization}

Figure 2 shows the results of the magnetization as a function of temperature for the $\mathrm{Fe}-\mathrm{C}$ thin films (samples (1) (3)) prepared by using composite targets (1) (3)).

From the design of the targets, it is expected that the composition of $\mathrm{C}$ increases with increasing number of

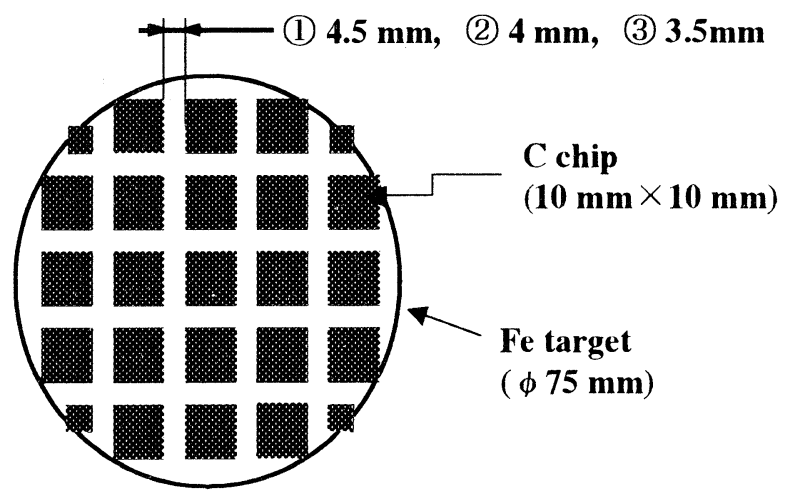

Fig. 1 Design of the composite target for IBS. 


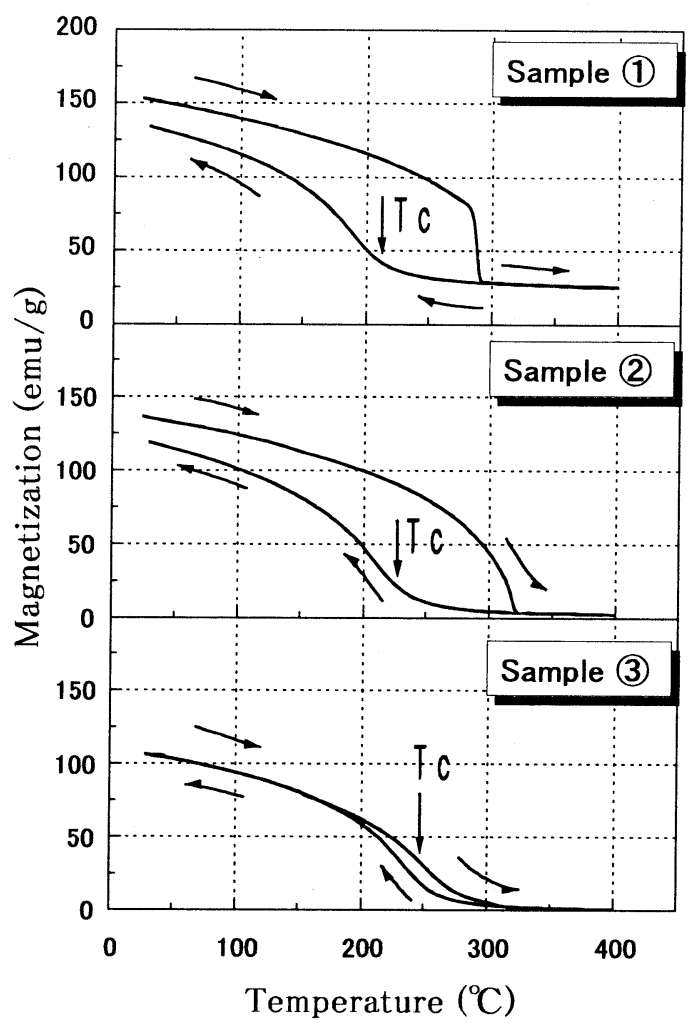

Fig. 2 Magnetization as a function of temperature at 10 kOe for sample(1)- (3). Vertical arrows indicate Tc for each sample in the cooling process.

samples. None of the magnetization versus temperature (M-T) curves were repeatable during the heating and the cooling processes. As-deposited films are amorphous and crystallized during heating up to $400{ }^{\circ} \mathrm{C}$. For sample(1), the rapid decrease in magnetization at around $280^{\circ} \mathrm{C}$ corresponds to crystallization of $\mathrm{Fe}_{3} \mathrm{C}$ from an amorphous state. To confirm the crystallization, we performed XRD measurements before and after the rapid decrease in magnetization. The XRD pattern under $280^{\circ} \mathrm{C}$ showed that the state was still amorphous, but the pattern above $280^{\circ} \mathrm{C}$ showed a crystalline state. As a result, it is considered that the crystallization temperature $\left(\mathrm{T}_{\text {crys. }}\right)$ of sample (1) is about $280{ }^{\circ} \mathrm{C}$. The extrapolated Curie temperature for the amorphous state of sample (1) is estimated at around $330{ }^{\circ} \mathrm{C}$. For sample (2), Tc and $\mathrm{T}_{\text {crys. }}$ overlap each other, as can be seen in Fig. 2. For sample (3), the Curie temperature for the amorphous state was estimated at $265^{\circ} \mathrm{C}$. Though it is not clear in the figure, a step in the magnetic susceptibility is observed at around $320{ }^{\circ} \mathrm{C}$, which corresponds to $\mathrm{T}_{\text {crys. }}$ for sample(3). Accordingly, $\mathrm{T}_{\text {crys. }}$ increases with increasing $\mathrm{C}$ composition. In contrast, $\mathrm{Tc}$ of amorphous $\mathrm{Fe}-\mathrm{C}$ decreases with increasing $\mathrm{C}$ composition. Even at $400{ }^{\circ} \mathrm{C}$, sample (1) still shows a small amount of magnetization caused by the precipitated pure $\mathrm{Fe}$ phase, whereas the magnetization disappears from samples (2) and (3) at this temperature.

After cooling to room temperature, the magnetization was $120.5 \mathrm{emu} / \mathrm{g}$ for sample (2). This value agrees with the bulk magnetization $(122-130 \mathrm{emu} / \mathrm{g})$ at $10 \mathrm{kOe}^{4), 5}$. The Curie temperature (Tc) was estimated from the $\mathrm{M}^{2}-\mathrm{T}$
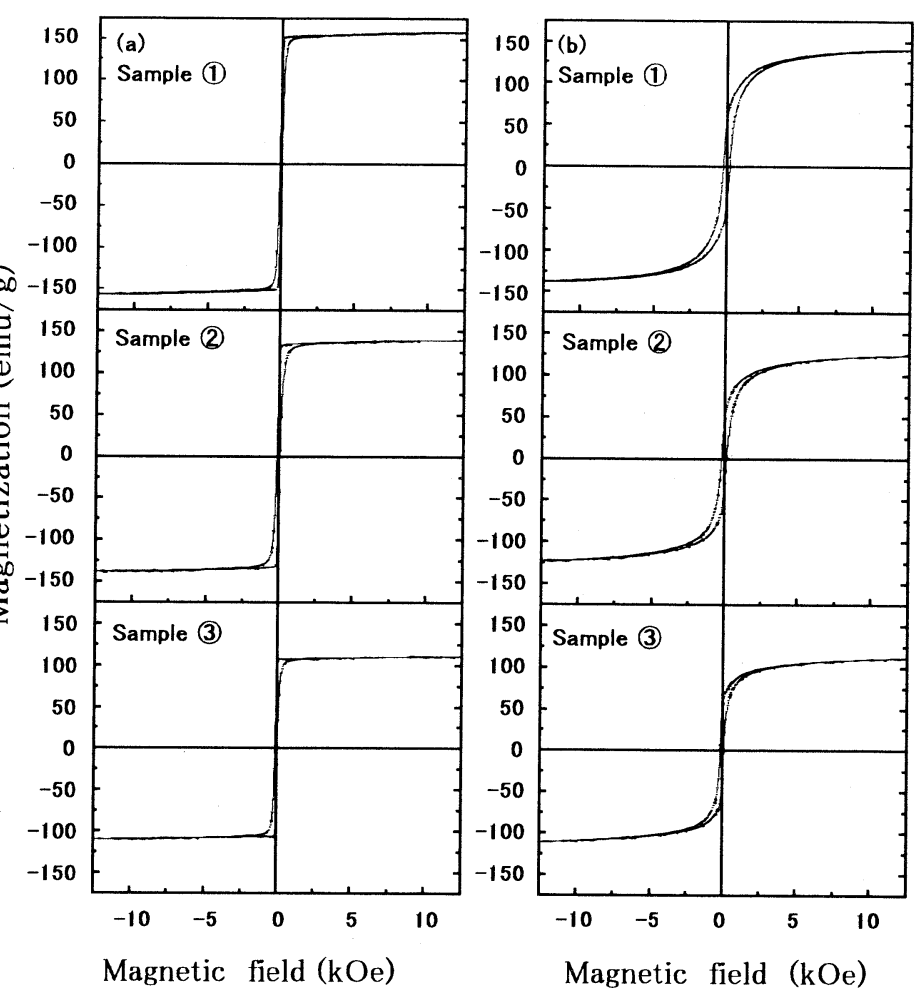

Fig. 3 Magnetization curves for samples (1) - (3) (a) as-deposited and (b) after heating to $400^{\circ} \mathrm{C}$

plot for each sample. The estimated Tc's are shown by the vertical arrows in Fig. 2. The estimated Tc for sample (2) was $227 \pm 5^{\circ} \mathrm{C}$ which almost matches that of bulk $\mathrm{Fe}_{3} \mathrm{C}^{4), 5), 13)}$. It is considered that the slight difference in Tc for $\mathrm{Fe}_{3} \mathrm{C}$ between samples (1) and (2) is due to the solubility of $\mathrm{C}$ in $\mathrm{Fe}_{3} \mathrm{C}$. For sample (3), the Tc is estimated to be $247 \pm 5^{\circ} \mathrm{C}$, which agree well with the Tc of the $\mathrm{Fe}_{5} \mathrm{C}_{2}$ phase described in a later section.

Figure 3 shows magnetization curves for samples (1)(3), (a) as-deposited and (b) after heating to $400^{\circ} \mathrm{C}$. The as-deposited samples show a smaller coercive force than the heated samples. The magnetization at $10 \mathrm{kOe}$ decreases with increasing carbon composition. The results of magnetization measurement for the heated

Table 1 Magnetic properties for samples (1)-(3) after heating.

\begin{tabular}{|l|c|c|}
\hline & $\mathrm{M}(\mathrm{emu} / \mathrm{g})(10 \mathrm{kOe})$ & $\mathrm{Tc}\left({ }^{\circ} \mathrm{C}\right)$ \\
\hline $\begin{array}{l}\text { Reference for } \\
\text { bulk } \mathrm{Fe}_{3} \mathrm{C}\end{array}$ & $122-130^{4), 5)}$ & $208-215^{4), 5), 13)}$ \\
\hline $\begin{array}{l}\text { Sample (1) } \\
\left(\mathrm{Fe}+\mathrm{Fe}_{3} \mathrm{C}\right)\end{array}$ & 140 & $213 \pm 5$ \\
\hline $\begin{array}{l}\text { Sample (2) } \\
\left(\mathrm{Fe}_{3} \mathrm{C}\right)\end{array}$ & 120.5 & $227 \pm 5$ \\
\hline $\begin{array}{l}\text { Sample (3) } \\
\left(\mathrm{Fe}_{3} \mathrm{C}+\mathrm{Fe}_{5} \mathrm{C}_{2}\right)\end{array}$ & 110 & $247 \pm 5$ \\
\hline
\end{tabular}




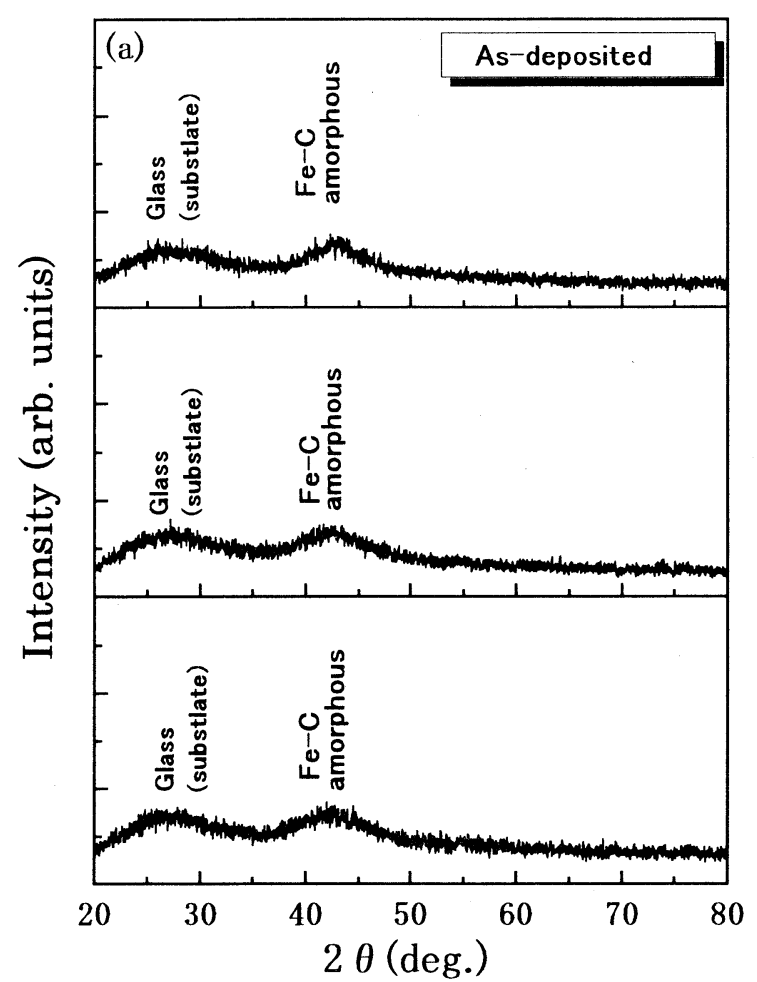

Fig. $4 \mathrm{X}$-ray diffraction patterns for samples

samples are listed in Table 1 . From the table, we conclude that sample (2) is $\mathrm{Fe}_{3} \mathrm{C}$ thin film without any impurity phase.

In order to confirm the structure of these thin films, an $\mathrm{X}$-ray diffraction analysis was carried out.

\subsection{X-Ray Diffraction}

Figure 4 shows the $\mathrm{X}$-ray diffraction patterns of (a) asdeposited and (b) heated samples. The as-deposited samples show a broad peak around $2 \theta=42^{\circ}$. This result indicates that the structures of as-deposited films are amorphous, and that samples become crystalline after heating to $400^{\circ} \mathrm{C}$. As shown in Fig. 4 (b), the heated samples of (1),(2), and (3) consist of $\mathrm{Fe}_{3} \mathrm{C}+\alpha-\mathrm{Fe}, \mathrm{Fe}_{3} \mathrm{C}$, and $\mathrm{Fe}_{3} \mathrm{C}+\mathrm{Fe}_{5} \mathrm{C}_{2}{ }^{14), 15), 16)}$, respectively. It should be noted that sample (2) is $\mathrm{Fe}_{3} \mathrm{C}$ single phase. In contrast, sample (1) is Fe-rich and sample (3) is carbon-rich compared with the stoichiomctric $\mathrm{Fe}_{3} \mathrm{C}$. These results agree well with the magnetization measurement mentioned in the previous section. The remaining magnetization in sample (1) at $400^{\circ} \mathrm{C}$ is from segregated $\alpha$-Fe. It is considered that the rather high $\mathrm{Tc}$ for sample (3) is related to $\mathrm{Fe}_{5} \mathrm{C}_{2}$ phase. The Curie temperature for $\mathrm{Fe}_{5} \mathrm{C}_{2}$ is $247 \pm 3{ }^{\circ} \mathrm{C}$ 5),17), which agrees with the $247 \pm 5{ }^{\circ} \mathrm{C}$ measurement for the thin film. To confirm the hyperfine structures of the $\mathrm{Fe}_{3} \mathrm{C}$ thin film, Mössbauer spectroscopy measurement was carried out.

3.3 Conversion Electron Mössbauer Spectroscopy

The hyperfine structure of the sample with target (2), which is considered to be stoichometric $\mathrm{Fe}_{3} \mathrm{C}$ from magnetization measurement and XRD, was measured by conversion electron Mössbauer spectroscopy (CEMS). Figure 5 shows the Mössbauer spectra and the results of analysis for a film with a thickness of $5000 \AA$, (a) as-deposited and (b) after annealing at $400^{\circ} \mathrm{C}$ for 1 hour. The dots in the figure show the experimental results and

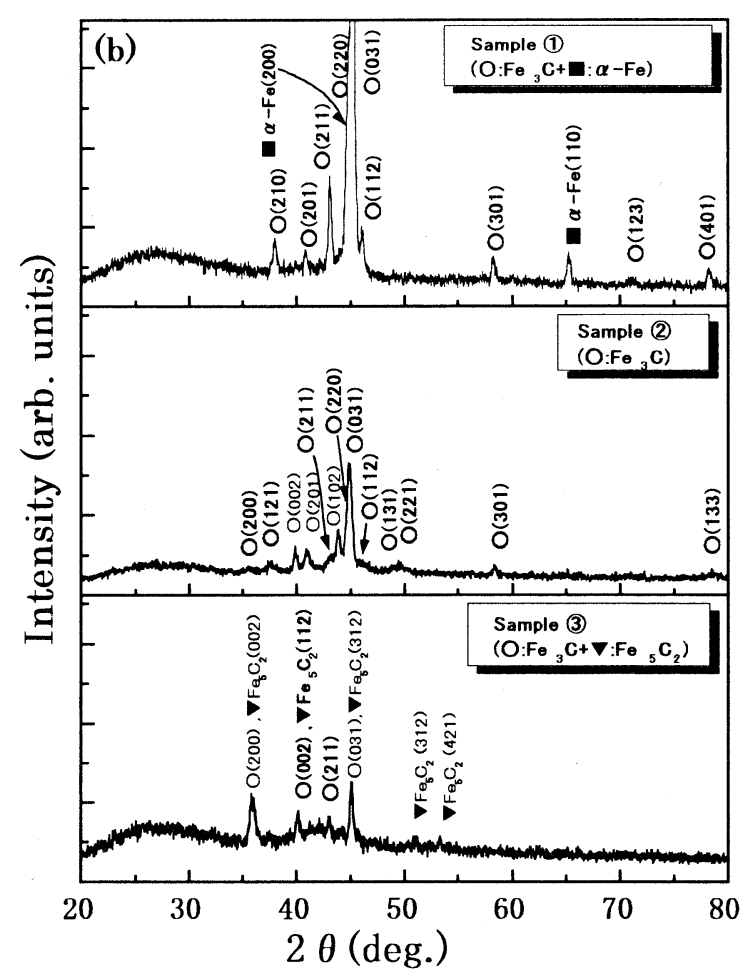

(a) as-deposited and (b) after heating to $400^{\circ} \mathrm{C}$.
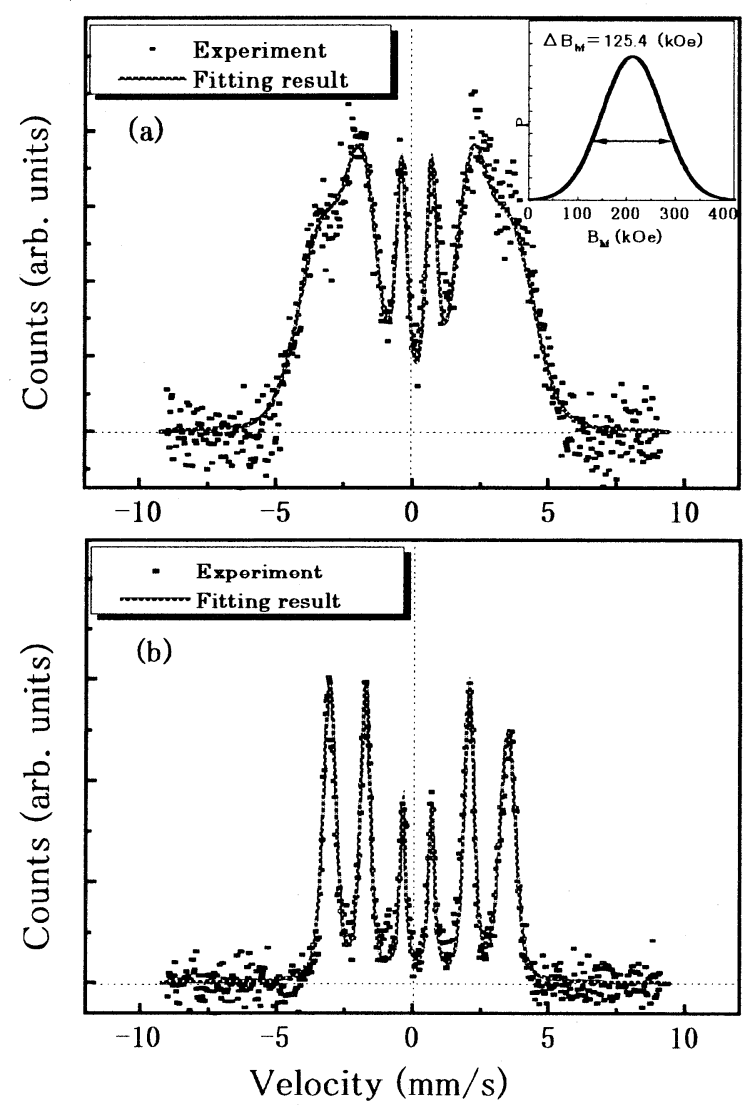

Fig. 5 Mössbauer spectra and the results after analysis for the film (5000 $\AA$ ) made from target (2), (a) as-deposited and (b) after annealing at $400^{\circ} \mathrm{C}$ for 1 hour. 
Table 2 Central values of the hyperfine parameters obtained after analysis of the CEMS spectrum compared with those of bulk $\mathrm{Fe}_{3} \mathrm{C}$.

\begin{tabular}{|c|c|c|c|}
\hline & As-deposited & Annealed & $\begin{array}{c}\text { Refenence for } \\
\text { bulk Fe } \mathrm{C}^{8 \text { 8),19),20) }}\end{array}$ \\
\hline $\mathrm{B}_{\mathrm{hf}}(\mathrm{kOe})$ & $212 \pm 3$ & $205 \pm 3$ & $208-210$ \\
\hline IS $(\mathrm{mm} / \mathrm{s})$ & $0.17 \pm 0.01$ & $0.20 \pm 0.01$ & $0.18-0.30$ \\
\hline QS $(\mathrm{mm} / \mathrm{s})$ & $0.00 \pm 0.01$ & $0.03 \pm 0.01$ & $0.01 \pm 0.05$ \\
\hline
\end{tabular}

the solid line shows the analyzed result of the fitting by a least mean square method using sextet Lorenz functions. The spectrum for as-deposited film (Fig. 5(a)) show fairly broad peaks, which are typical for an amorphous state. We assumed a Gaussian distribution for the analysis. The distribution curve obtained by the fitting is shown in the right inset of Fig. 5(a). The mean value of the hyperfine field is estimated to be $212 \mathrm{kOe}$ and the half width of the distribution is $125 \mathrm{kOe}$. The isomer shift (IS) and the quadrupole shift (QS) are estimated to be $0.17 \mathrm{~mm} / \mathrm{sec}$ and $0.00 \mathrm{~mm} / \mathrm{sec}$, respectively. The intensity ratio of the sextet for this spectrum is $3: 2: 1: 1: 2: 3$, which means that the direction of the magnetic moment is randomly oriented. The Mössbauer spectrum and the results of analysis for an annealed sample are shown in Fig. 5(b). This spectrum shows a sharp line width compared with the as-deposited state, and no other impurity phase is observed. However, the sextet shows a slightly asymmetric intensity ratio. This asymmetric spectrum is typical for the distribution of IS and QS. Accordingly, this spectrum is fitted with a distribution of the hyperfine field, isomer shift, and quadrupole shift. ${ }^{21)}$ In this fitting, we assume linear distribution of the isomer shift and quadrupole shift with respect to the hyperfine field distribution. The mean values of $B_{h f}, I S$ and $Q S$ are 205 $\pm 3 \mathrm{kOe}, 0.20 \pm 0.01 \mathrm{~mm} / \mathrm{s}$, and $0.03 \pm 0.01 \mathrm{~mm} / \mathrm{s}$, respectively. The values agree well with those of bulk $\mathrm{Fe}_{3} \mathrm{C}\left(\mathrm{B}_{\mathrm{hf}}=208-210 \mathrm{kOe}, \mathrm{IS}=0.18-0.30 \mathrm{~mm} / \mathrm{s}\right.$, and $\mathrm{QS}=0.01 \pm 0.05 \mathrm{~mm} / \mathrm{s})^{18), 19), 20)}$. The intensity ratio of the sextet is $3: 2.4: 1: 1: 2.4: 3$, which indicates that the average direction of the magnetic moment is canted 30 deg. from in-plane to out-of-plane. The clearest difference between as-deposited and after annealed sample is in the distribution of the hyperfine field. The narrow line width for the spectrum of the annealed sample is consistent with crystallization of $\mathrm{Fe}_{3} \mathrm{C}$. This result suggests that the present $\mathrm{Fe}_{3} \mathrm{C}$ thin film includes no impurity phase with some distortion. Table 2 shows the results of the analysis of the hyperfine parameters compared with those for bulk $\mathrm{Fe}_{3} \mathrm{C}$. From this table, it is shown that the $\mathrm{Fe}_{3} \mathrm{C}$ thin film has almost the same values as bulk $\mathrm{Fe}_{3} \mathrm{C}$.

\section{Summary}

1. The $\mathrm{Fe}-\mathrm{C}$ thin films were prepared by ion-beam sputtering (IBS), using a composite target. A singlephase $\mathrm{Fe}_{3} \mathrm{C}$ thin film was obtained from as-deposited amorphous $\mathrm{Fe}-\mathrm{C}$ thin films after heating to $400^{\circ} \mathrm{C}$.

2. Hyperfine parameters were estimated from the conversion electron Mössbauer spectroscopy (CEMS). The mean values of the hyperfine field $\left(B_{h f}=205 \mathrm{kOe}\right)$, isomer shift (IS $=0.20 \mathrm{~mm} / \mathrm{s}$ ), and quadrupole shift $(\mathrm{QS}=0.03 \mathrm{~mm} / \mathrm{s})$ for this film show similar values to those of bulk $\mathrm{Fe}_{3} \mathrm{C}$.

\section{References}

1) H. Lipton and N. J. Petch: J. Iron. Steel Inst., 142,95 (1940).

2) R. M.Bozorth, ed.: Ferromagnetism, p364 (IEEE Press, New York 1896-1981).

3) B. M. Drapkin and G. M. Kimstach: The Physics of Metals and Metallography, Vol. 80, No. 2, 171 (1995).

4) M. M. P. Blum and R. Pauthenet: CR Acad. Sci., (Paris) 237,1501 (1953).

5) L. J. E. Hofer and E. M. Cohn: J. Am. Chem. Soc., 81,1576 (1959).

6) M. Takahashi, Y. Takahashi, and H. Shoji: IEEE Trans. Magn., 37,2179 (2001).

7) Y. Takahashi, H. Shoji, and M. Takahashi: J. Magn. Magn. Mat., 210, 333 (2000).

8) T. Kobayashi, S. Ootomo, and N. Kumasaka : J. Appl. Phys., 61, 5480 (1987)

9) T. Kobayashi, R. Nakatani, S. Ootomo, N. Kumasaka, and K. Shiiki: J. Appl. Phys., 64, 3157 (1988)

10) S. J. Li, H. Yumoto, M. Shimotomai, M. Ishihara : Thin Solid Films, 345, 23 (1999).

11) S. J. Li, M. Ishihara, H. Yumoto, T. Aizawa, and M. Shimotomai: Thin Solid Films, 316, 100 (1998).

12) K. Kanaya, K. Hojou, K. Koga and K. Toki: Jpn. J.Appl. Phys. 12, 1297 (1973).

13) M. E. Nicholson: J. Metals, 9, 1 (1957).

14) J. P. Senateur and R. Fruchart: CR. Acad. Sci., 256, 3114 (1963).

15) K. H. Jack and S. Wild: Nature, 212, 248 (1966).

16) M. J. Duggin, L. J. E. Hofer: Nature, 212, 248 (1966).

17) J. P. Senateur, R. Fruchart, and A. Michel: $C R$ Acad. Sci., 255, 1615 (1962)

18) T. Shinjyo, F. Itoh, and H. Takaki: J. Phys. Soc. Jpn., 19, 1252 (1964).

19) H. Bernas, I. A. Campbell, and R. Fruchart: J. Phys. \& Chem. Solids, 28, 17 (1967)

20) H. Ino, T. Moriya, F. E. Fujita, Y. Maeda J. Phys. Soc. Jpn., 25, 88 (1968).

21) J. P. Kuang, M. Matsui, and K. Adachi: Journal De Physique, C8-135 (1988).

Received October 9, 2001; Accepted February 7, 2002 